\title{
Enlightened Self-interest in Altruism (ESIA)
}

\author{
Laura Vearrier ${ }^{1}$
}

Published online: 16 April 2020

(c) Springer Nature B.V. 2020

\begin{abstract}
Altruism and the medical profession have been linked throughout the history of medicine. Students are drawn to the calling of medicine because of altruistic values, dedication to service, and the desire to alleviate suffering and promote healing. Despite a dedication to these values, altruism in medicine is threatened by empathy erosion that develops in the clinical years of medical school and an increasing rate of medical student burnout. Currently, there are two widespread movements in medicine aimed at addressing the dual loss of altruism and physician and student burnout-professionalism and wellness. Despite widespread recognition of the problems and programs aimed at improving them, there has been little headway, and even calls to abandon altruism in the modern marketplace of medicine. What is needed is not an abandonment of a fundamental, defining value of the profession, but a reevaluation of the meaning of altruism in medicine and a framework that allows for students and physicians to provide altruistic care for a sustainable, rewarding career in the healing profession. This paper proposes the Enlightened Self-Interest in Altruism (ESIA) model as an ethical framework to allow medical students to synergize the interests of the self with those they serve in a mutually beneficial relationship to improve patient care and the healthcare system at large. The ESIA model acknowledges that egoism and altruism are intertwined, dynamic motivators of behavior. In the enlightened self-interest approach, the interests of the group are also the interests of the self. The physician-patient relationship is a dyad in which egoism and altruism may converge in an enlightened way that acknowledges that the interests of one are the interests of the whole. This is a paradigm shift from the historical view of egoism and altruism as opposing motivations. This paper will present the threats to altruism, explore the interface of egoism and altruism in a clinical vignette, and then present the ESIA framework as an educational approach to aligning the interests of providers and patients to prevent burnout and promote altruism.
\end{abstract}

Keywords Altruism · Empathy $\cdot$ Burn out $\cdot$ Professionalism $\cdot$ Education, medical · Ethics

Laura Vearrier

lvearrier@umc.edu

Extended author information available on the last page of the article 


\section{Introduction}

This paper proposes Enlightened Self-Interest in Altruism (ESIA) as a new framework for understanding altruism in medicine and renewing medicine's dedication to altruism by aligning the interests of the self with the interests of service to others in a synergistic relationship. Altruism and the medical profession have been linked throughout the history of medicine (McGaghie et al. 2002; Feldman 2017). While there are a myriad of reasons why students choose to matriculate in medical school, altruism and desires to alleviate suffering and promote healing are common features in the calling to medicine (Kutner and Brogan 1980; Győrffy et al. 2016; McGaghie et al. 2002; Coulehan and Williams 2001; Feldman 2017). Despite a dedication to these values, altruism in medicine is threatened by empathy erosion and burn out which are increasingly prevalent among medical students. Currently, there are two widespread movements in medicine aimed at addressing the dual loss of altruism and physician and student burnout-professionalism and wellness. Despite widespread recognition of the problems and programs aimed at improving them (Yasin et al. 2019), there has been little headway, and even calls to abandon altruism in the modern marketplace of medicine.

What is needed is not an abandonment of altruism as a fundamental, defining value of the profession, but a re-evaluation of the meaning of altruism in medicine and a framework that allows for students and physicians to provide altruistic care for a sustainable, rewarding career in the healing profession via advancement of selfinterests that align with service to others. This paper proposes the ESIA model as an ethical framework to allow medical students to synergize the interests of the self with those they serve in a mutually beneficial relationship to improve patient care and the healthcare system at large.

The ESIA model acknowledges that egoism and altruism are intertwined, dynamic motivators of behavior. In the enlightened self-interest approach, the interests of the group are also the interests of the self. The physician-patient relationship is a dyad in which egoism and altruism may converge in an enlightened way that acknowledges that the interests of one are the interests of the whole. Students pursue medicine for self-fulfillment in cognitive, emotional, technical, and social desiresall of which can then be used to benefit others. When the needs of the self are fulfilled, one can serve others, which in turn is a self-interest, as service to others can be deeply rewarding and provide a sense of accomplishment, pride, and interconnectedness. ESIA is a paradigm shift from the historical view of egoism and altruism as opposing motivations where altruism is self-sacrifice in the self-flagellation culture of medical school. This paper will present the threats to altruism, explore the interface of egoism and altruism in a clinical vignette, and then present the ESIA framework as an educational approach to aligning the interests of providers and patients to move from surviving to thriving in order to promote altruism. 


\section{Background: Altruism in Medicine}

\section{History}

In Aequanimitas, Sir William Osler states that "the profession of medicine is distinguished from all others by its singular beneficence. It alone does the work of charity in a Jovian and God-like way, dispensing with free hand truly Promethean gifts" (Osler 1932, p. 282). Altruism has been a defining feature of medicine throughout time. It is a core component of the ancient Hippocratic Oath (Feldman 2017). The commitment to care for persons with infectious diseases despite personal risks was explained by understanding medicine as a moral enterprise, driven by the virtuous acts of providers (Zuger and Miles 1987). These virtuous acts are not a historic past of plagues, but ongoing, as seen with the recent Ebola outbreak. Despite inadequate personal protections, healthcare workers (defined as doctors, nurses, and midwives) in Africa continued to provide care to infected persons, and the epidemic resulted in the deaths of hundreds of healthcare workers (Yakubu et al. 2016; Evans et al. 2015).

Healthcare depends on the altruism not just of doctors and nurses but of other members of society. It relies on altruistic acts such as donating blood and organs, participating in human research, and sharing health information. These acts may involve bodily discomfort, unpredictable adverse effects, or psychological stress. While the altruism of these acts has been challenged, the personal rewards are typically nominal compared to the act itself, with the greatest reward often being the emotional satisfaction that results from the charitable act such as giving blood (Ferguson and Lawrence 2016).

Over the last twenty years, medicine as a profession has attempted to renew its dedication to altruism as part of the professionalism movement. In the Physician Charter, altruism is declared the fundamental principle that is necessary for fostering trust in the physician-patient relationship (ABIM Foundation et al. 2002). The Medical Schools Objective Project, sponsored by the Association of American Medical Colleges, states in bold text "Physicians must be altruistic" (Association of American Medical Colleges 1998, p. 4). The beginning of medical school has been considered to be a crossing of a threshold and a transition in one's social role in society defined by professionalism (Robins et al. 2002). In the American Board of Internal Medicine's Project Professionalism, it states "altruism is the essence of professionalism" (Stobo et al. 1995, p. 5). Medical school admissions committees seek out applicants who they believe will choose altruism as a guiding principle in their careers (Albanese et al. 2003).

These calls to professionalism and altruism by professional societies are in stark contrast to the increasing empathy erosion among medical professionals. It has been questioned whether altruism can even exist in the modern marketplace of medicine. In an editorial, Roger Jones describes "a growing feeling that altruism in medicine, if not dying, is at least declining" (Jones 2002, p. 624). Today's culture of medicine is considered to be "hostile to altruism" (Coulehan 2005, p. 892). Some authors advocate for abandoning altruism in medical education as medicine 
is a compensated profession, and this financial compensation makes altruism an untenable goal (Burks and Kobus 2012; Glannon and Ross 2002). Glannon and Ross (2002) argue that the most fundamental feature of the medical profession is not altruism, but a fiduciary responsibility to patients in which physicians have an obligation to act in a patient's best medical interest. They argue that altruism cannot exist in this context of a professional obligation. However, physicians have always received compensation for their services, and the concepts of professional obligation and financial compensation are insufficient to overthrow altruism as a defining feature, ideal, and inspiration in medicine.

\section{The Threats to Altruism: Burnout and the Hidden Curriculum}

Physician burnout is considered a public health crisis (Lacy and Chan 2018). Burnout rates among physicians and physicians-in-training exceed 50\% (West et al. 2018). Physician burnout is a work-related syndrome that involves emotional exhaustion, compassion fatigue, depersonalization, and a reduced sense of accomplishment. Burnout causes deterioration in mental and physical health leading to increased substance abuse, depression, and suicidality.

Physician burnout rates adversely affect the entire healthcare system. For patients, physician burnout results in lower quality of care, increased medical errors, and decreased patient satisfaction (Halbesleben and Rathert 2008; West et al. 2018). Physicians with burnout are less likely to identify with medicine as a calling, thereby losing their passion for the art and practice of medicine (Jager et al. 2017).

For the healthcare system, physician burnout results in increased healthcare costs, decreased physician productivity, and decreased access to care as physicians leave the profession (Eckleberry-Hunt et al. 2009; West et al. 2018). While the problem of physician burnout is widely recognized, uncertainty exists on how to address it. Studies have reported that interventions at the organizational and individual levels can be effective at decreasing burnout, but substantive overall improvement is considered unlikely until coordinated efforts at the national, state, leadership, and organizational levels are implemented (Shanafelt et al. 2017).

A variety of factors contribute to burnout, but most are related to healthcare systems and organizations. The main factors relate to work load, excessive clerical work, cumbersome electronic medical records and documentation processes, and loss of autonomy in the workplace (Shanafelt et al. 2017; West et al. 2018). Factors related to physician burnout are summarized in Table 1.

Burnout begins in medical school. In a survey of medical students, $45 \%$ of respondents met the criteria for burnout, and burnout was higher for students in the clinical years (Dyrbye et al. 2006). Among students with burnout, there was a rate of depression and self-reported binge drinking. There has been increased attention to the "hidden curriculum" in medical training as the source of empathy erosion that occurs in the clinical years.

The term hidden curriculum was first coined in the 1970s to describe the tacit ways in which the social and cultural aspects of education impart knowledge and shape behaviors (McLaren 2015; Wear 1998). The hidden curriculum exists outside 
Table 1 Healthcare system and organization factors contributing to physician burnout

- High work hours

- Night and weekend calls

- Inefficient electronic medical records

- Computerized order entry

- Insufficient support staff

- Excessive documentation required by insurers for reimbursement

- Complex preapproval processes for patients to have procedures and studies

- Cumbersome or duplicative certification requirements: licensing, credentialing, continuing medical education

- Lack of work-home integration

- Negative leadership behaviors

- Negative interpersonal relationships in the workplace

- Limited opportunities for mentorship and interprofessional collaboration

- Lack of social support at work

- Lack of respect from leadership, colleagues, and patients

- Limited opportunities for advancement

- Fear of involvement in a medical malpractice lawsuit

- Involvement in a medical malpractice lawsuit

of what is formally taught. And, while teachers and learners continuously engage with the hidden curriculum, they typically do so unwittingly.

Several studies have reported that empathy decreases in the clinical years of medical school (Chen et al. 2007; Hojat et al. 2004, 2009; Newton et al. 2008). It has been considered ironic that empathy decreases during the time that the educational focus shifts from classroom didactics to patient-centered activities (Hojat et al. 2009). This may be ironic, but is it not predictable? Medical students are working in the same healthcare system that pulls providers away from the bedside to in front of a computer screen. They have less autonomy in the workplace, and they have long clinical hours after which they are studying for exams. They are shuffled from one rotation to the next without a constant peer group. All of these stressors are occurring as they enter a work environment characterized by human suffering and death. Over half of the attending physicians under whom they are training are themselves burned out, thereby limiting their cognitive and emotional energy to be teachers, role models, and mentors.

In the pre-clinical years, the formal curriculum teaches ethical values, collegiality, patient-centered care, respect, and communication. But, this formal curriculum is subverted by the hidden curriculum in the clinical years. As medical training takes on an apprenticeship form, the culture of the environment becomes even more important. Medical students see attendings and residents use cynical and derogatory humor to ridicule patients with psychiatric disease, poor hygiene, substance use disorders, self-inflicted harm, obesity and other conditions, in what has been called the "humor games" in medicine (Wear et al. 2006). Humor requires engaging with people with similar senses of humor, and is a form of cultural-insider knowledge 
that lures in medical students who are seeking a sense of belonging in the hospital culture (Wear et al. 2006). Derogatory and disrespectful language is seen throughout the hospital and not just targeted at patients, but other providers and services, which is in stark contrast to the formal curricular values of respect, inclusivity, and cultural humility (Szauter et al. 2003).

The hidden curriculum also promotes emotional detachment in favor of a focus on factual knowledge. Specialization is glorified and it is implied that students who pursue primary specialties do so because they are not academically competitive enough to matriculate to a specialty training program (Mahood 2011). Students have described a hierarchical and competitive atmosphere where teaching by humiliation is not uncommon in the clinical years (Lempp and Seale 2004). Michael Fine describes the marketplace of medicine where sophisticated technologies rule in the clinical environment, leaching the profession of compassion (Fine 2018). When students enter this de-personalized technology-driven market, their interests shift from serving others to doing good for themselves by pursuing lucrative subspecialties.

\section{The Interface of Altruism and Egoism}

\section{The Timeless Debate}

Philosophical discussions on the relationship between self and other and egoism and altruism have been ongoing since the ancient Greek philosophers Aristotle (384-322 B.C.) and Plato (c.428-347 B.C.). Aristotle discussed the primacy of selflove and altruism as deriving from self-love (Kahn 1981). Interpretations of Plato's Republic view the concept of justice as emerging entirely from self-interest and not moral obligation (Altman 2009). The majority view among Renaissance and postRenaissance philosophers was that humans are egoistic and that our concern for others extends from our concern for ourselves (Batson et al. 2002).

Biology and psychology continue to engage in this ongoing debate. Darwin recognized that altruism challenged his theory of natural selection, in which each individual acts egoistically for self-preservation, when he observed eusocial insects sacrificing themselves for the group (Warneken and Tomasello 2009). The Darwinian model in which each organism's primary focus is on its own survival and reproduction is especially problematic for social animals, such as humans, who rely on each other and work cooperatively. Complex relationships emerge between the drive for individual self-promotion and cooperative social behaviors.

In studies of human behavior, infants as young as 14- to 18-months demonstrate helpful behaviors, such as helping another individual reach an object or open a cabinet, and they demonstrate these behaviors in the absence of external rewards, such as approval from an adult and without concern for things such as reciprocity or reputation (Warneken and Tomasello 2009). The authors conclude that this instrumental helping, in which an individual helps another achieve a goal, is the earliest manifestation of human altruism and that children are predisposed to altruism (Warneken and Tomasello 2009). In this model, socialization then builds upon this predisposition for altruism, but is not the primary driving force. This paper does not seek to 
resolve the timeless, dichotomous debate about altruism and universal egoism, but to demonstrate how altruism and enlightened self-interest may align.

\section{Altruism: A Definitional Quandary}

Despite the fact that altruism is considered a cornerstone of medicine, it remains a vague ideal. There is a lack of a conceptual framework or consensus on how to define, teach, and assess altruism in medicine. There is a "current conceptual chaos about altruism" (McGaghie et al. 2002, p. 374) that remains unresolved.

The English word altruism is derived from the French word altruisme, which was coined by philosopher August Comte. In his writings on positivism, he defined altruism as a "motivational state with the ultimate goal of increasing another's welfare" (Coulter et al. 2007, p. 341). Note that self-sacrifice is not part of this definition. Nor does this definition state that the self cannot also benefit, just that the ultimate goal must be the welfare of another-if there is concurrent benefit to the self, altruism is not necessarily nullified. The Merriam-Webster dictionary defines altruism as "unselfish regard for or devotion to the welfare of others" (Merriam Webster). Again, self-sacrifice is not required and a secondary benefit to the self does not invalidate altruism, as long as the motivation is not selfish.

\section{The Empathy-Altruism Model}

Empathy has been considered a primary source of altruism from medieval philosophers to contemporary psychologists (Batson et al. 2002). In the Empathy-Altruism hypothesis, empathy motivates individuals to help others and affords truly altruistic acts (Batson et al. 1981). There is significant evidence that feeling empathy for a person in need leads to helping behaviors (Batson et al. 1981; Coke et al. 1978; Dovidio et al. 1990; Eisenberg et al. 1989). There are egoistic and partially egoistic alternative explanations to empathy-altruism in the literature, with some of the predominant theories summarized in Table 2 (Batson 2010; Batson et al. 2002; Cialdini et al. 1987; Mikulincer et al. 2005).

\section{Motivations to Behaviors}

Egoism and altruism are motivations that result in behaviors. It is impossible to ever completely understand the motivations of others, as such an understanding would rely on self-reports, which are unreliable. Therefore, in the professional formation of medical students, it is behaviors that are observed, guided, and evaluated. Motivations that are altruistic, egoistic, or some combination of the two may produce the same, desirable action. For illustrative purposes, consider the following vignette and some of the possible egoistic, or partially egoistic motivations, that may be present in addition to altruistic motivations. 
Table 2 Egoistic or partially egoistic alternative explanations to true altruism

\begin{tabular}{ll}
\hline Framework & Explanation \\
\hline Aversive-arousal reduction & $\begin{array}{c}\text { An individual helps another in need in order to decrease their own } \\
\text { suffering that results from an empathetic response. } \\
\text { Helping another in order to vicariously experience the positive } \\
\text { effects on another }\end{array}$ \\
People learn through socialization that there is a moral obliga- \\
tion to help others, so they do so to avoid punishments such as \\
judgement by others or shame. \\
Helping others in pursuit of praise, respect, and recognition from \\
society \\
Helping others to gain as sense of personal pride and experience \\
the joy associated with helping others \\
Helping behaviors are directed at benefiting the group to which \\
one belongs, as opposed to an individual \\
Collectivism \\
The goal of helping is to uphold an impartial, moral principle \\
(e.g., justice) consistent with internal values
\end{tabular}

\section{Vignette: Part 1}

Sara is a 4th year medical student on her emergency medicine rotation. Ten minutes before the end of her shift, a nurse walks by the doctors' desk and says, "the patient who was just brought in by EMS is having 10/10 pain similar to a previous kidney stone and is actively vomiting, can anyone see the patient?" The sounds of the patient's screams and intermittent retching can be heard in the background. The resident, who is busy caring for a critically ill patient, states that he can't at the moment. The nurse looks somewhat irritated. Sara says, "I'll see the patient." When Sara enters the room, she sees the patient writhing in pain.

Sara performs a history and physical examination. She presents the case to one of the attending physicians who writes an order for pain medication based on Sara's report. Sara talks to the nurse about the order in order to expedite the process. When she goes back to check on the patient, she is relieved to see that the patient appears much more comfortable after the pain medication. The patient is very thankful. The nurse also thanks Sara. The attending physician was impressed by Sara's history and physical presentation and her ability to develop a differential diagnosis and treatment plan and gives her a good evaluation for the shift.

That evening Sara gets home an hour later than expected because she had stayed late to care for the patient. When she walks into her apartment, she sees her roommate sitting on the couch and exclaims, "Oh no! I completely forgot about our dinner plans. I am too exhausted to still go out tonight, but I promise I'll make it up to you tomorrow."
Possible egoistic motivations

Aversive-arousal reduction-Sara wishes to decrease the sounds of the screams and retching.

Punishment avoidance-Sara does not want to be negatively judged by the nurse.

Principlism-Sara feels there should be justice in access to care and that the care of one patient should not prevent the care of this patient in a timely fashion.

Collectivism-Sara is part of the emergency department care team, and she wants to do her part to ease the workload of the team.

Other-Sara has not yet cared for a patient with a kidney stone and her education would benefit from the patient.

\section{Reward Seeking:}

Personal-Sara takes personal pride and has a sense of joy regarding her ability to care for the patient.

Social-Sara is thanked by the patient and the nurse. She benefits by a good evaluation by the attending.

This vignette shows how egoistic or partially egoistic motivations may be desirable, beneficial to patient care, and lead to altruistic behaviors. Providing 
medical care requires being part of a team. Desires to help the team and to be respected by the team improve team dynamics. Adherence to the core principles of medical ethics provides an essential framework for students, and commitments to values such as justice are important for advocacy and public health. Students' commitment to their own education ultimately improves their ability to care for future patients. And, the element of joy should not be minimized. Getting personal satisfaction out of being a physician is an essential component for career longevity and alacrity in patient care.

Part 2 of the vignette will now delve into potential sources of burnout and elements of the hidden curriculum.

\begin{tabular}{|c|c|}
\hline Vignette: Part 2 & Sources of burnout and the hidden curriculum \\
\hline $\begin{array}{l}\text { That night, Sara stays up late studying to prepare } \\
\text { for the emergency medicine shelf exam. The } \\
\text { next morning, the resident who was working } \\
\text { yesterday is there again, and greets her with, } \\
\text { "Hey, medical student-so the patient you saw } \\
\text { yesterday just ended up being a drug-seeker. } \\
\text { Her CT scan showed no kidney stone and she } \\
\text { was screaming at the nurses all night for pain } \\
\text { medication." } \\
\text { Another resident who is typing at a computer } \\
\text { chimes in, "Oh yeah, I know that patient- did } \\
\text { you fall for her kidney stone story? She would } \\
\text { stop retching if she stopped sticking her fingers } \\
\text { down her throat." Sara feels some of the joy that } \\
\text { she felt at the end of the shift yesterday begin } \\
\text { to slip away and a mix of anger, shame, and } \\
\text { exhaustion take its place. The resident continues, } \\
\text { "Maybe I should do a pain management fellow- } \\
\text { ship--then at least I won't have to work nights } \\
\text { and weekends and I would make more money." } \\
\text { Sara asks if they can discuss the management } \\
\text { of kidney stones at some point that day. The } \\
\text { resident replies, "Sure, if I ever get through all } \\
\text { the charts backed up from yesterday." } \\
\text { Near the end of her shift, Sara is asked to place } \\
\text { IVs and do EKGs because there is insufficient } \\
\text { nursing and technician staff. She tells the } \\
\text { resident that she needs to leave on time today } \\
\text { because of personal obligations. He replies, "I } \\
\text { thought you wanted to go into emergency medi- } \\
\text { cine?" Sara texts her roommate that she is going } \\
\text { to have to miss dinner again and leaves only } \\
\text { when the resident turns to her and says, "Okay, } \\
\text { now you can go home." }\end{array}$ & $\begin{array}{l}\text { Physiologic stresses-inadequate sleep } \\
\text { Hierarchy-The resident (not corrected by others, } \\
\text { or mimicking the behaviors of others) considers it } \\
\text { acceptable to call Sara "medical student." } \\
\text { The culture of burnout-Sara is witnessing the } \\
\text { effects of pervasive burnout in medicine, which } \\
\text { can create a toxic environment. } \\
\text { Witnessing negative attitudes - The resident refers } \\
\text { to the patient as a "drug seeker." } \\
\text { Experiencing negative attitudes-The second } \\
\text { resident's comments are belittling to Sara with an } \\
\text { implication that she did something wrong. } \\
\text { Sub-specialization and higher income as motiva- } \\
\text { tors-especially when the joy of caring for } \\
\text { patients is diminished } \\
\text { Cumbersome electronic health records-taking } \\
\text { away from patient care and educational activities } \\
\text { Insufficient staffing-increases stress on other pro- } \\
\text { viders and slows patient care } \\
\text { Hierarchy-The resident implies that Sara will } \\
\text { sacrifice her grade and ability to get a spot in } \\
\text { emergency medicine if she does not follow orders. } \\
\text { Culture of self-sacrifice-It is the norm for physi- } \\
\text { cians to sacrifice elements of their personal lives. }\end{array}$ \\
\hline
\end{tabular}




\section{Enlightened Self-interest in Altruism (ESIA)}

Part 2 of the vignette depicts some of the pervasive elements of burnout and the hidden curriculum that cause physiologic, cognitive, and emotional stress. When basic needs of the self are not met or are threatened, it compromises the ability to serve others. In striving for altruism, medical students must meet their personal needs to a sufficient degree to foster a sustainable career. The concept of egoism leading to altruism seems counter-intuitive and requires an educational framework to appropriately guide it, which I have termed Enlighted Self-Interest in Altruism (ESIA). ESIA is an educational framework for professional formation with the ultimate goal and reward of a fulfilling career, a state of being a part of something greater than oneself, and altruism.

The concept of enlightened self-interest was first described by Alexis de Tocqueville as the principle of interest rightly understood in his 1835 book Democracy in America (de Tocqueville 2003). Tocqueville reconciles the idea that every man's interests are focused on the self with acts of self-sacrifice with the concept that serving the community is in one's own self-interest- "it serves as a truth that man serves himself in serving his fellow-creatures, and that his private interest is to do good" (de Tocqueville 2003, p. 594). He describes how "man is brought home to himself by an irresistible force" (2003, p. 594). As attempts to stop the omnipotent force would be in vain, efforts should be not on stopping it, but directing it and applying it in such a way to allow man to be more virtuous. People can be motivated to sacrifice part of their time or property for the welfare of the group or community from which they benefit.

In contrast to pure altruism, which timeless debates have failed to resolve if even possible, the concept of enlightened self-interest is easily accessible. Enlightened self-interest is accessible because it negates the debate over the underlying or base motivation and focuses on aligning self-interest with the interest of others to result in behaviors that benefit all. Medical school is a self-actualization professional development in which students are learning to serve others by developing their own cognitive, emotional, and procedural skills. Tocqueville describes how enlightened self-interest does not result in great acts of self-sacrifice but rather in smaller, more regular, daily acts of self-sacrifice. ESIA for medical students presents medical students with attainable altruistic goals that can co-exist with the colossal task of becoming a physician.

Incorporating the ESIA framework into the formal medical school curriculum includes education on the drives underlying altruism, the fostering of altruism through practice, and appreciation of the alignment of self-interests and service to others. ESIA guides students in self-fulfillment in the medical profession as opposed to arduous self-sacrifice. Self-interests in medicine that foster altruism include desires for intellectual development, respect and recognition of service, membership and belonging in professional and peer groups, physical and mental rest and recovery to allow for maximal job performance, non-career interests to allow a refreshed return to work, positive work environments, inspirational mentors, and responsive leadership (Fig. 1). Individual students are motivated by different self-interests in varying degrees. ESIA guides and develops the self-interests that promote altruism 
to produce physicians that are advocates for patients as well as themselves, other providers, and the profession as a whole. ESIA asks students to consider what will produce their own personal long-term career satisfaction.

Altruism itself is a reward. It has been hypothesized that altruistic acts are an essential part of maintaining career enthusiasm as a physician (McGaghie et al. 2002). The practice and reinforcement of altruism foster future altruism. Observing altruistic acts that are positively reinforced is considered to encourage future altruism (McGaghie et al. 2002). Witnessing altruism is an elevating experience and promotes altruism in others (Farsides 2007). More altruistic people have been reported to have better mental and physical health (Post 2007). ESIA makes altruism selfperpetuating with the reciprocal relationship with enlightened self-interest.

ESIA must be sustainable. ESIA not only allows for personal benefit but encourages it in order to maximize the benefits for all. Motivations of self-benefit are necessary for career longevity and to improve patient care. In ESIA, self-interest and altruism are not in tension. ESIA differs from wellness programs in that it is not just for the individual student—it is for the benefit of the student as well as patients, medical care teams, institutions, and health systems. A review of wellness programs for students found that the majority of programs focused on improving access to mental health services and reducing barriers to access, including stigma (Slavin et al. 2014). ESIA is not an ancillary program but an integral component of becoming a physician and sustaining a career.

Professional formation programs typically focus on what a physician owes society. ESIA also asks, "What do I get out of being a physician?" Physicians are allowed to enjoy the advantages afforded to them by what has been called the social contract of medicine with society (Cruess et al. 2010) instead of denying the advantages or feeling less altruistic because of them. Cooperative behavior is considered only to likely persist when there is direct or indirect reciprocity (Jones 2002). ESIA evokes reciprocity with an evaluation of benefits that for some students may be overlooked or taken for granted.

While enlightened self-interest is attainable, sustainable, and beneficial, ESIA acknowledges that the learners need guidance and education to always return to altruism. When Tocqueville first described altruism, he acknowledged that even though it was self-evident, persons still need guidance on how to understand and

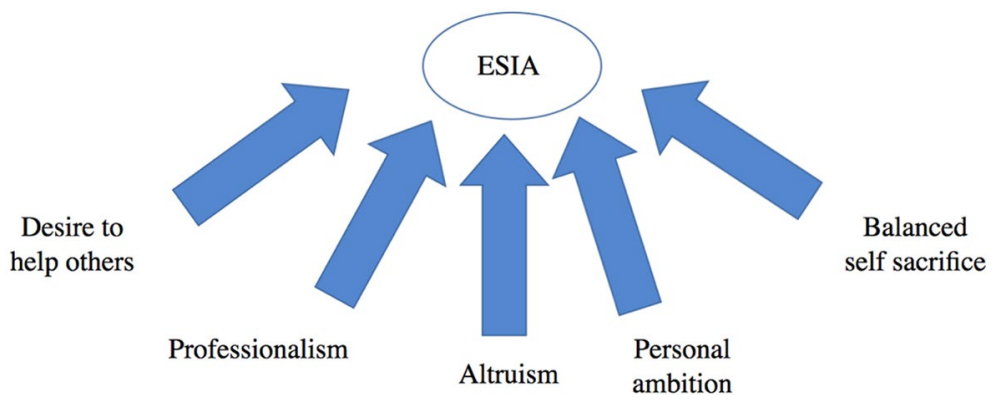

Fig. 1 Elements contributing to ESIA 
direct personal interests in order to prevent excesses in egoism. Altruism has been described not as an innate, fixed trait, but an inherent capacity that must be developed (Krebs and Van Hesteren 1994).

As an example, consider ESIA applied to volunteer student-run clinics (SRCs). It is estimated that about half of all medical schools operate one or more SRCs that provide care to vulnerable populations (Rubenstein et al. 2016). Medical students experience high levels of stress, related to the heavy workload as well as other factors, which can lead to anxiety and depression (Dahlin et al. 2005; Fares et al. 2016; Heinen et al. 2017). Volunteering at a clinic increases a student's workload. An ESIA approach to an SRC would guide the student in seeing the self-interests in volunteering, not the self-sacrifice.

The self-interests of volunteering at an SRC include a variety of educational opportunities. SRCs provide preclinical students a unique clinical opportunity. In addition to learning clinical skills to augment the classroom, SRCs allow the learners to be the primary providers and take on leadership roles (Mikhaeil et al. 2019). Students gain an understanding of interprofessional collaboration and health systems and learn to advocate for patients (Mikhaeil et al. 2019; Ellett et al. 2010). Additionally, students have reported that volunteering at SRCs helps them stay connected to their sense of purpose and improves their overall well-being (Smith et al. 2012).

Volunteer students serve the community by providing care to vulnerable and marginalized populations that may not have access to healthcare otherwise. Patients seen at student-run clinics report overall positive experiences and high satisfaction (Ellett et al. 2010; Mischell et al. 2017; Lu et al. 2018). The positive experiences of the students and patients may also have long-term benefits. Students who volunteer at SRCs have reported increased interested in serving vulnerable populations and increased interest in future careers in primary care.

For faculty who volunteer to oversee the clinical care at SRCs, it has been reported that the most common motivating factor is working with students (Rubenstein et al. 2016). Medical schools can use ESIA to increase volunteers and improve the experience for faculty and students, thereby increasing community outreach. Students should be encouraged to think about how they can benefit from volunteering. When they arrive at the clinic, they should discuss their goals with faculty. After the experience, reflection on the experience may be encouraged by activities such as debriefing with the volunteer team, blogging about their experiences with an optional platform to share blogs with peers, or another creative outlet that encourages personal growth towards becoming a physician and experiencing the joy in serving others.

\section{Conclusion}

The ESIA model presented in this paper proposes a framework in which self-interests and altruism exist in a synergistic relationship. The prevalence of burnout and empathy erosion in medical school demands a shift from the culture of self-sacrifice and self-flagellation. ESIA replaces the tension between self-interests and altruism 
with an alliance. Altruism is itself a self-interest in that it can be uplifting and promote a sense of purpose and well-being. ESIA promotes the intertwined relationship of self-interests and altruism to produce the desirable actions and behaviors in medical students. During a time when the relationship of medicine and altruism seems to be deteriorating, ESIA seeks to serve as bridge. ESIA makes altruism sustainable with the appropriate and guided incorporation of the self-interests.

\section{References}

ABIM Foundation, American Board of Internal Medicine, ACP-ASIM Foundation, American College of Physicians, American Society of Internal Medicine, \& European Federation of Internal Medicine. (2002). Medical professionalism in the new millennium: A physician charter. Annals of Internal Medicine, 136(3), 243-246.

Albanese, M. A., Snow, M. H., Skochelak, S. E., Huggett, K. N., \& Farrell, P. M. (2003). Assessing personal qualities in medical school admissions. Academic Medicine, 78(3), 313-321.

Altman, W. H. (2009). Altruism and the art of writing: Plato, Cicero, and Leo Strauss. Humanitas, 22(1/2), 69-98.

Association of American Medical Colleges. (1998). Learning objectives for medical student education: Guidelines for medical schools. Washington, D.C.: Association of American Medical Colleges.

Batson, C. D. (2010). Empathy-induced altruistic motivation. In Prosocial motives, emotions, and behavior: The better angels of our nature. https://doi.org/10.1037/12061-001.

Batson, C. D., Ahmad, N., Lishner, D. A., \& Tsang, J. (2002). Empathy and altruism. In S. J. Lopez \& C. R. Synder (Eds.), The Oxford handbook of hypo-egoic phenomena (pp. 161-174). New York: Oxford University Press.

Batson, C. D., Duncan, B. D., Ackerman, P., Buckley, T., \& Birch, K. (1981). Is empathic emotion a source of altruistic motivation? Journal of Personality and Social Psychology, 40(2), 290-302.

Burks, D. J., \& Kobus, A. M. (2012). The legacy of altruism in health care: The promotion of empathy, prosociality and humanism. Medical Education, 46(3), 317-325.

Chen, D., Lew, R., Hershman, W., \& Orlander, J. (2007). A cross-sectional measurement of medical student empathy. Journal of General Internal Medicine, 22(10), 1434-1438.

Cialdini, R. B., Schaller, M., Houlihan, D., Arps, K., Fultz, J., \& Beaman, A. L. (1987). Empathy-based helping: Is it selflessly or selfishly motivated? Journal of Personality and Social Psychology, 52(4), 749-758.

Coke, J. S., Batson, C. D., \& McDavis, K. (1978). Empathic mediation of helping: A two-stage model. Journal of Personality and Social Psychology, 36(7), 752-766.

Coulehan, J. (2005). Today's professionalism: Engaging the mind but not the heart. Academic Medicine, 80(10), 892-898.

Coulehan, J., \& Williams, P. C. (2001). Vanquishing virtue: The impact of medical education. Academic Medicine, 76(6), 598-605.

Coulter, I. D., Wilkes, M., \& Der-Martirosian, C. (2007). Altruism revisited: A comparison of medical, law and business students' altruistic attitudes. Medical Education, 41(4), 341-345.

Cruess, S. R., Cruess, R. L., \& Steinert, Y. (2010). Linking the teaching of professionalism to the social contract: A call for cultural humility. Medical Teacher, 32(5), 357-359.

Dahlin, M., Joneborg, N., \& Runeson, B. (2005). Stress and depression among medical students: A crosssectional study. Medical Education, 39(6), 594-604.

De Tocqueville, A., \& Reeve, H. (2003). Democracy in America (Vol. 10). Washington D.C.: Regnery Publishing.

Dovidio, J. F., Allen, J. L., \& Schroeder, D. A. (1990). Specificity of empathy-induced helping: Evidence for altruistic motivation. Journal of Personality and Social Psychology, 59(2), 249-260.

Dyrbye, L. N., Thomas, M. R., Huntington, J. L., Lawson, K. L., Novotny, P. J., Sloan, J. A., et al. (2006). Personal life events and medical student burnout: A multicenter study. Academic Medicine, 81(4), 374-384.

Eckleberry-Hunt, J., Lick, D., Boura, J., Hunt, R., Balasubramaniam, M., Mulhem, E., et al. (2009). An exploratory study of resident burnout and wellness. Academic Medicine, 84(2), 269-277. 
Eisenberg, N., Miller, P. A., Schaller, M., Fabes, R. A., Fultz, J., Shell, R., et al. (1989). The role of sympathy and altruistic personality traits in helping: A reexamination. Journal of Personality, 57(1), 41-67.

Ellett, J. D., Campbell, J. A., \& Gonsalves, W. C. (2010). Patient satisfaction in a student-run free medical clinic. Family Medicine, 42(1), 16-18.

Evans, D. K., Goldstein, M., \& Popova, A. (2015). Health-care worker mortality and the legacy of the Ebola epidemic. The Lancet Global Health, 3(8), e439-e440.

Fares, J., Al Tabosh, H., Saadeddin, Z., El Mouhayyar, C., \& Aridi, H. (2016). Stress, burnout and coping strategies in preclinical medical students. North American Journal of Medical Sciences, 8(2), $75-81$.

Farsides, T. (2007). The psychology of altruism. Psychologist-Leicester, 20(8), 474-477.

Feldman, M. D. (2017). Altruism and medical practice. Berlin: Springer.

Ferguson, E., \& Lawrence, C. (2016). Blood donation and altruism: The mechanisms of altruism approach. ISBT Science Series, 11(S1), 148-157.

Fine, M. (2018). Health care revolt: How to organize, build a health care system, and resuscitate democracy-all at the same time. Oakland: PM Press.

Glannon, W., \& Ross, L. F. (2002). Are doctors altruistic? Journal of Medical Ethics, 28(2), 68-69.

Győrffy, Z., Birkás, E., \& Sándor, I. (2016). Career motivation and burnout among medical students in Hungary - Could altruism be a protection factor? BMC Medical Education, 16(1), 182. https://doi. org/10.1186/s12909-016-0690-5.

Halbesleben, J. R., \& Rathert, C. (2008). Linking physician burnout and patient outcomes: Exploring the dyadic relationship between physicians and patients. Health Care Management Review, 33(1), 29-39.

Heinen, I., Bullinger, M., \& Kocalevent, R.-D. (2017). Perceived stress in first year medical studentsassociations with personal resources and emotional distress. BMC Medical Education, 17(1), 4.

Hojat, M., Mangione, S., Nasca, T. J., Rattner, S., Erdmann, J. B., Gonnella, J. S., et al. (2004). An empirical study of decline in empathy in medical school. Medical Education, 38(9), 934-941.

Hojat, M., Vergare, M. J., Maxwell, K., Brainard, G., Herrine, S. K., Isenberg, G. A., et al. (2009). The devil is in the third year: A longitudinal study of erosion of empathy in medical school. Academic Medicine, 84(9), 1182-1191.

Jager, A. J., Tutty, M. A., \& Kao, A. C. (2017). Association between physician burnout and identification with medicine as a calling. Mayo Clinic Proceedings, 92(3), 415-422.

Jones, R. (2002). Declining altruism in medicine: Understanding medical altruism is important in workforce planning. British Medical Journal Publishing Group, 324(7338), 624-625.

Kahn, C. H. (1981). Aristotle and altruism. Mind, 90(357), 20-40.

Krebs, D. L., \& Van Hesteren, F. (1994). The development of altruism: Toward an integrative model. Developmental Review, 14(2), 103-158.

Kutner, N. G., \& Brogan, D. R. (1980). The decision to enter medicine: Motivations, social support, and discouragements for women. Psychology of Women Quarterly, 5(2), 341-357.

Lacy, B. E., \& Chan, J. L. (2018). Physician burnout: The hidden health care crisis. Clinical Gastroenterology and Hepatology, 16(3), 311-317.

Lempp, H., \& Seale, C. (2004). The hidden curriculum in undergraduate medical education: Qualitative study of medical students' perceptions of teaching. BMJ, 329(7469), 770-773.

Lu, K. B., Thiel, B., Atkins, C. A., Desai, A., Botwin, A., Povlow, M. R., et al. (2018). Satisfaction with healthcare received at an interprofessional student-run free clinic: Invested in training the next generation of healthcare professionals. Cureus, 10(3), e2282.

Mahood, S. C. (2011). Medical education: Beware the hidden curriculum. Canadian Family Physician, 57(9), 983-985.

McGaghie, W. C., Mytko, J. J., Brown, W. N., \& Cameron, J. R. (2002). Altruism and compassion in the health professions: A search for clarity and precision. Medical Teacher, 24(4), 374-378.

McLaren, P. (2015). Life in schools: An introduction to critical pedagogy in the foundations of education. London: Routledge.

Merriam Webster. (n.d.). Altruism. https://www.merriam-webster.com/dictionary/altruism. Accessed 13 Apr 2020.

Mikhaeil, J., Ng, B., Durr, M.-R., Shah, S., \& Chiu, E. (2019). Student-run clinic association: The next generation of health system collaboration. University of Ottawa Journal of Medicine, 9(2), 11-14. 
Mikulincer, M., Shaver, P. R., Gillath, O., \& Nitzberg, R. A. (2005). Attachment, caregiving, and altruism: Boosting attachment security increases compassion and helping. Journal of Personality and Social Psychology, 89(5), 817-839.

Mischell, S., Yegya-Raman, N., Frenchu, K., \& Lin, K. (2017). Patient expectations and satisfaction when using a student-run health clinic. Journal of Student-Run Clinics, 3(1), 1-7. https://journalsrc .org/index.php/jsrc/article/view/23/23. Accessed 13 Apr 2020.

Newton, B. W., Barber, L., Clardy, J., Cleveland, E., \& O'Sullivan, P. (2008). Is there hardening of the heart during medical school? Academic Medicine, 83(3), 244-249.

Osler, S. W. (1932). Aequanimitas; with other addresses. Philedelphia, PA: Blakiston.

Post, S. G. (2007). Altruism and health: Perspectives from empirical research. Oxford: Oxford University Press.

Robins, L. S., Braddock, C. H., III, \& Fryer-Edwards, K. A. (2002). Using the American Board of Internal Medicine's "Elements of Professionalism" for undergraduate ethics education. Academic Medicine, 77(6), 523-531.

Rubenstein, W., Rifkin, R., Huber, B., Pedowitz, E., Rabkin, J., Thomas, D., et al. (2016). What drives faculty to volunteer at a student-run clinic for the underserved? Journal of Student-Run Clinics, 2(1), 1-6.

Shanafelt, T. D., Dyrbye, L. N., \& West, C. P. (2017). Addressing physician burnout: The way forward. JAMA, 317(9), 901-902.

Slavin, S. J., Schindler, D. L., \& Chibnall, J. T. (2014). Medical student mental health 3.0: Improving student wellness through curricular changes. Academic Medicine, 89(4), 573-577.

Smith, S. D., Johnson, M. L., Rodriguez, N., Moutier, C., \& Beck, E. (2012). Medical student perceptions of the educational value of a student-run free clinic. Family Medicine-Kansas City, 44(9), 646-649.

Stobo, J., Kohen, J., Kimball, H., LaCombe, M., Schechter, G., \& Blank, L. (1995). Project professionalism. Philadelphia: American Board of Internal Medicine.

Szauter, K., Williams, B., Ainsworth, M. A., Callaway, M., Bulik, R., \& Camp, M. G. (2003). Student perceptions of the professional behavior of faculty physicians. Medical Education Online, 8(1), 4338.

Warneken, F., \& Tomasello, M. (2009). The roots of human altruism. British Journal of Psychology, 100(3), 455-471.

Wear, D. (1998). On white coats and professional development: The formal and the hidden curricula. Annals of Internal Medicine, 129(9), 734-737.

Wear, D., Aultman, J. M., Varley, J. D., \& Zarconi, J. (2006). Making fun of patients: Medical students' perceptions and use of derogatory and cynical humor in clinical settings. Academic Medicine, 81(5), 454-462.

West, C. P., Dyrbye, L. N., \& Shanafelt, T. D. (2018). Physician burnout: Contributors, consequences and solutions. Journal of Internal Medicine, 283(6), 516-529.

Yakubu, A., Folayan, M. O., Sani-Gwarzo, N., Nguku, P., Peterson, K., \& Brown, B. (2016). The Ebola outbreak in Western Africa: Ethical obligations for care. Journal of Medical Ethics, 42(4), 209-210.

Yasin, L., Stapleton, G. R., \& Sandlow, L. (2019). Medical professionalism across cultures: A literature review. MedEdPublish,. https://doi.org/10.15694/mep.2019.000191.1.

Zuger, A., \& Miles, S. H. (1987). Physicians, AIDS, and occupational risk: Historic traditions and ethical obligations. JAMA, 258(14), 1924-1928.

Publisher's Note Springer Nature remains neutral with regard to jurisdictional claims in published maps and institutional affiliations.

\section{Affiliations}

\section{Laura Vearrier $^{1}$}

1 Department of Emergency Medicine, University of Mississippi Medical Center, 2500 North State Street, Jackson, MS, USA 